\title{
Leguminosas isoladas e consorciadas com milheto em diferentes sistemas de manejo do solo no feijão orgânico
}

\author{
Legumes not associated and associated with millet in different soil \\ management systems in organic bean
}

\author{
Marisol Rivero Herrada ${ }^{1 *}$, Wilson Mozena Leandro² e Enderson Petrônio de Brito Ferreira ${ }^{3}$ \\ ${ }^{1}$ Universidade Técnica Estadual de Quevedo, Campus Ing. Manuel Haz Álvarez, km 1.5 vía a Santo Domingo de los Tsáchilas. 120554 Quevedo, Ecuador. \\ *Autora responsable (mriveroh59@gmail.com) \\ ${ }^{2}$ Universidade Federal de Goiás (UFG), Campus Samambaia. Nova Veneza, km zero. Caixa Postal 131. 74690-900 Goiânia, Goiás, Brasil. \\ ${ }^{3}$ Pesquisador da Embrapa Arroz e Feijão. Rodovia GO-462, km 12. Caixa Postal 179. 74375-000Santo Antônio de Goiás-GO, Brasil,
}

\section{RESUMO}

Vários estudos têm demonstrado as vantagens da utilização de plantas de cobertura em manter ou melhorar a qualidade do solo e produtividade da cultura. No entanto, os efeitos dessa gestão em feijão comum orgânico em condições de savana, ainda são desconhecidos. Este estudo teve como objetivo avaliar o efeito de leguminosas, mucuna (Mucuna pruriens (L.) DC, feijão guandu (Cajanus cajan L.) HUTH, feijão de porco (Canavalia ensiformis), crotalária (Crotalária juncea) em monocultura e em consórcio com milheto (Pennisetum glaucum L.) R. Br. de 1810, na produção de grãos no feijoeiro comum em sistema orgânico de produção sob o sistema do manejo do solo convencional e plantio direto. $\mathrm{O}$ experimento foi realizado com a cultivar BRS Pontal, em um delineamento em blocos casualizados. Aos 90 dias após a germinação das plantas de feijão foram avaliadas, o número de vagens por planta (NVP), número de grãos por vagem (NGV), número de grãos por planta (NGP), peso de 100 grãos (M100G) e produção de grãos. Os resultados mostraram que o número de vagens, número de grãos e produtividade do feijoeiro no sistema orgânico, foram influenciados pelas culturas de cobertura do solo e sistemas manejo do solo, com destaque para mucuna associados com milheto e sistema de plantio direto, que proporcionou o melhor desempenho destes parâmetros. A maior produção de grãos foi observado com a mucuna associados com milho em sistema de plantio direto. A produtividade média de grãos orgânicos foi de $3.8 \mathrm{Mg} \mathrm{ha}^{-1}$. A análise de agrupamento mostrou um efeito marcante de sistemas de manejo do solo sobre os componentes de produção do feijoeiro.

Cita recomendada:

Rivero Herrada, M., W. Mozena Leandro e E. P. de Brito Ferreira. 2017. Leguminosas isoladas e consorciadas com milheto em diferentes sistemas de manejo do solo no feijão orgânico. Terra Latinoamericana 35: 293-299.
Palavras chave: plantas de cobertura, Phaseolus vulgaris $L$., produtividades.

\section{SUMMARY}

Several studies have demonstrated the benefits of using cover crops to maintain or improve soil quality and crop productivity. However, the effects of this management with organic common bean in conditions of savannah are still unknown. The objective of this study was to evaluate the effect of legumes, mucuna (Mucuna pruriens (L.) DC, pigeon pea (Cajanus cajan L.) HUTH, jack or pig bean (Canavalia ensiformis), sunn hemp (Crotalaria juncea) in monoculture and intercropped with pearl millet (Pennisetum glaucum L.) R. Br. 1810 , on grain production in common bean in organic production under systems of conventional and notillage soil management. The experiment was conducted with the cultivar BRS Pontal, arranged in a randomized block design. Bean plants were evaluated 90 days after germination, recording the number of pods per plant, number of grains per pod (NGV), number of grains per plant (NGP), weight of 100 grains (M100G) and grain production. The results showed that the number of pods, number of grains and grain yield of common bean in the organic system were influenced by the cover crops and soil management. Mucuna associated with millet and no-tillage system was outstanding, producing the best performance in these parameters. The highest grain yield was observed with the mucuna associated with maize in the no-tillage system. The average productivity of organic grain was $3.8 \mathrm{Mg} \mathrm{ha}^{-1}$. The cluster analysis showed a remarkable effect of soil management systems on bean production components.

Recibido: abril de 2016. Aceptado: septiembre de 2017. Publicado en Terra Latinoamericana 35: 293-299. 
Index words: cover crops, Phaseolus vulgaris L., yields.

\section{INTRODUÇÃO}

O aumento da procura pelos consumidores por produtos orgânicos e o crescente interesse dos agricultores por sistemas alternativos de produção que aumentem a rentabilidade, melhorem a qualidade de vida do meio rural e preservem a capacidade produtiva do solo em longo prazo, têm impulsionado a busca de informações sobre a contribuição dos sistemas de preparo do solo e de plantas de cobertura na manutenção da fertilidade do solo sob cultivo orgânico (Cunha et al., 2011).

O feijoeiro comum (Phaseolusvulgaris L.) constituise em uma das mais importantes fontes proteicas na dieta humana em países em desenvolvimento das regiões tropicais e subtropicais. O cultivo orgânico desta cultura tem crescido de forma significativa dada à demanda de crescimento do consumo deste produto (Posse et al., 2010).

Segundo Ambrosano et al. (2004), com a prática da adubação verde, é possível recuperar a fertilidade do solo proporcionando aumento do teor de matéria orgânica, da capacidade de troca de cátions e da disponibilidade de macro e micronutrientes: formação e estabilização de agregados; melhoria da infiltração de água e aeração; diminuição diuturna da amplitude de variação térmica; controle de nematoides e, no caso das leguminosas, incorporação ao solo do nutriente nitrogênio, efetuada através da fixação biológica. Por meio do consórcio de leguminosas e gramíneas, com elevada produção de biomassa, podem-se conciliar proteção e adubação do solo (Oliveira et al., 2002).

A escolha das espécies adequadas para cobertura vegetal é fundamental para a manutenção ou elevação da fertilidade do solo, influenciando a produtividade das culturas em sucessão. Nogueira et al. (2006) afirmam que os resíduos da cobertura vegetal, em especial das leguminosas interferem positivamente, de forma geral, nos componentes produtivos e na produtividade do feijoeiro.

O milheto (Pennisetum glaucum) tem sido uma planta de cobertura bastante utilizada em safrinha, em razão de seu crescimento rápido e elevada produção de fitomassa e ciclagem de nutrientes em condições de déficit hídrico. Apresenta alta resistência quanto à decomposição de seus resíduos, com tempo de meia vida da fitomassa na superfície do solo de até 131 dias após seu manejo, em razão da elevada relação $\mathrm{C} / \mathrm{N}$, o que pode resultar em maior persistência da palhada sobre solo. Todavia, o ciclo fenológico curto dessa espécie semeada em safrinha, na região do Cerrado, faz com que a decomposição e liberação da fitomassa iniciem-se de forma prematura em relação à época de semeadura das culturas anuais (Timossi et al., 2007).

O elevado crescimento radicular do milheto pode auxiliar na descompactação do solo pela formação de canais preferenciais para o escoamento da água e crescimento de raízes das culturas anuais sucessoras. De acordo com Gonçalves et al. (2006) o uso de milheto para a descompactação em solo de Cerrado é viável, obtendo em 30 dias elevada produção de fitomassa e densidade de comprimento radicular em camadas compactadas de solo.

Segundo Giacomini et al. (2003), o consórcio entre diferentes espécies proporciona a produção de uma fitomassa cuja relação $\mathrm{C} / \mathrm{N}$ é intermediária àquela das espécies em monocultura. Outro aspecto a ser destacado refere-se à maior produção de matéria seca (MS) das espécies de cobertura em relação à vegetação espontânea do tratamento em pousio. Para Cunha et al. (2011) o preparo do solo e o uso de plantas de cobertura são importantes práticas no sistema orgânico de cultivo. Com o crescente interesse dos agricultores nesse sistema, visando ao aumento da rentabilidade e melhoria da qualidade de vida no meio rural, além da preservação da capacidade produtiva do solo em longo prazo, é necessário gerar informações sobre a contribuição dessas práticas na manutenção da qualidade do solo.

O preparo do solo para plantio de feijoeiro comum pode ser realizado através do sistema, plantio convencional e sistema de plantio direto. O sistema de plantio convencional envolve operações de preparação de solo com máquinas agrícolas que removem a superficie do solo e as coberturas antes da semeadura. Ao contrário o sistema de plantio direto, não há o revolvimento do solo e é realizada a rotação das culturas deixando as coberturas sobre superfície do solo, as quais contribuem para a recuperação ou manutenção das qualidades do solo e estabilização da produtividade. Em condições de produção orgânica no Cerrado, Ferreira et al. (2011a) relataram a produtividade de grãos em feijoeiro comum atinge de 1.5 e $2.0 \mathrm{Mg} \mathrm{ha}^{-1}$ sob sistema de plantio convencional e de sistema de plantio direto, respectivamente. Além disso, os mesmo autores também relataram uma alta 
correlação da produção de grãos com a quantidade de nitrogênio disponibilizada pelas plantas de cobertura do solo.

Portanto, torna-se importante o conhecimento sobre estes aspectos para alcançar produtividade estáveis e reduzir custos da cultura do feijoeiro comum em sistemas de produção orgânica sob condições da agricultura familiar. Com base no exposto, este trabalho objetivou avaliar o efeito de leguminosas isoladas e consorciadas com milheto em os sistemas de manejo do solo convencional e plantio direto sobre o crescimento da planta e produtividade do feijoeiro comum em sistema de produção orgânica.

\section{MATERIAL E MÉTODOS}

O trabalho foi conduzido na Estação Experimental em Agroecologia da Embrapa Arroz e Feijão, no município de Santo António de Goiás, Estado de Goiás. O solo foi caracterizado como Latossolo VermelhoAmarelo (Ferralsol), textura média, distrófico com antecedente de manejo sem uso de defensivos agrícolasnos últimos cico anos e manejo da área com adubos verdes, o que proporciona as características exigidas para um sistema de produção orgânica.

Alocalizaçõe da área experimental foi de $16^{\circ} 40^{\prime} 22^{\prime \prime}$ de latitude sul e $49^{\circ} 15^{\prime}$ '19" Oeste. Relevo caracterizado por ser moderadamente plano a levemente ondulado. O clima enquadra-se com B2 WB 42' segundo a classificação de Köppen. Apresenta temperatura média de $21{ }^{\circ} \mathrm{C}$, com máxima de $29{ }^{\circ} \mathrm{C}$ e mínima de $15{ }^{\circ} \mathrm{C}$. Umidade relativa anual $41.5 \%$, precipitação pluviométrica média anual de $1487.2 \mathrm{~mm}$ e insolação total 2645.7 horas (Silva et al., 2010).

Foram avaliadas quatro espécies de leguminosas como espécies de coberturas: mucuna (Mucuna pruriens L.) DC, feijão guandu (Cajanus cajan), feijão de porco (Canavaria ensiformes), crotálaria (Crotalária juncea) e milheto (Pennisetum glaucum L.) R. BR. 1810. As quatro espécies foram plantadas em consórcio ou isoladas. Os sistemas de manejo foram: convencional e plantio direto. $\mathrm{O}$ delineamento foi em blocos ao acaso em arranjo fatorial $(4 \times 2 \times 2) \mathrm{com}$ 16 tratamentos e quatro repetições.

As plantas de leguminosas isoladas e consorciadas com milheto foram semeadas em Janeiro de $2011 \mathrm{com}$ uma distância entre sulco de $0.50 \mathrm{~cm}$. Aos 60 dias após da semeadura foram manejadas no solo, incorporadas no sistema convencional e deixada na superfície do solo em sistema de p. As leguminosas isoladas e consorciadas apresentaram um aporte meia de massa seca total de $10 \mathrm{Mg} \mathrm{ha}^{-1}$.

Após o manejo das plantas realizou-se a semeadura de feijoeiro comum cultivar BRS Pontal em Junho de 2011, com semeadora adubadora, semeada e manejada sob o sistema convencional e, também sob plantio direto em parcelas constituídas de noves linhas da cultura com espaçamento de $0.45 \mathrm{~m}$ e com comprimento de $5 \mathrm{~m}$, totalizando área de $22.5 \mathrm{~m}^{2}$. Sendo que a área útil das parcelas foi constituída das cinco linhas centrais, desprezando-se as duas linhas laterais, em ambos os lados, e $0.50 \mathrm{~m}$ nas extremidades de cada linha da área da parcela.

As avaliações da produtividade e seus componentes foram efetuados aos 90 dias após a semeadura, sendo coletadas e avaliadas dez plantas por parcela da área útil. As variáveis avaliadas foram: número de vagens por planta $(\mathrm{NV})$, número de grãos por vagens $(\mathrm{NGV})$, número de grãos por planta (NGP), massa de cem grãos (M100G), e produtividade, quantificados após a colheita e a debulha mecânica das plantas, corrigindose o teor de água para $13 \%$.

Os dados foram submetidos a uma análise de variância, sendo as médias comparadas pelo teste de Tukey a $5 \%$ de probabilidade. Os dados dos componentes de produtividade e a produção de grãos do feijoeiro comum foram usados em análise multivariada por agrupamento em dendrograma de similaridade com o objetivo de visualizar a divisão dos tratamentos avaliados em função do sistema de manejo do solo. Foi utilizado o programa Statistica. 10.0 para Windows (StatSoft, 2011).

\section{RESULTADOS E DISCUSSÃO}

Os componentes de rendimento e a produção da cultura do feijoeiro comum em função das plantas de cobertura e do sistema de consorciação são apresentados na Tabela 1.

Os resultados mostraram que existem diferenças significativas pra a interação dos fatores, coberturas e o fator sistemas de cultivo., tendo sido observados efeitos significativos dos tratamentos sobre os componentes de rendimento: número de vagens $(\mathrm{NV})$, número de grãos por planta (NGP) e produção, para os quais a mucuna consorciada com milheto proporcionou maiores valores em relação ao feijão guandu consorciado com milheto. 
Tabela 1. Componentes de rendimento e produtividade de grãos em feijoeiro comum em função das plantas de cobertura do solo.

\begin{tabular}{|c|c|c|c|c|c|}
\hline Coberturas & NV & NGV & NGP & M100G & Produção \\
\hline & Planta & Vagem & Planta & $\mathrm{g}$ & $\mathrm{Mg} \mathrm{ha}^{-1}$ \\
\hline MUC & $13.67 \mathrm{a}$ & $6.4 \mathrm{a}$ & $76.9 \mathrm{a}$ & $28.7 \mathrm{a}$ & $4.42 \mathrm{a}$ \\
\hline MUI & $10.12 \mathrm{ab}$ & $5.8 \mathrm{a}$ & $53.5 \mathrm{ab}$ & $28.1 \mathrm{a}$ & $3.30 \mathrm{ab}$ \\
\hline CJC & $10.91 \mathrm{ab}$ & $5.6 \mathrm{a}$ & $56.0 \mathrm{ab}$ & $28.7 \mathrm{a}$ & $3.24 \mathrm{ab}$ \\
\hline CJI & $13.02 \mathrm{ab}$ & $5.7 \mathrm{a}$ & $70.8 \mathrm{ab}$ & $26.8 \mathrm{a}$ & $4.39 \mathrm{ab}$ \\
\hline FPC & $11.90 \mathrm{ab}$ & $6.0 \mathrm{a}$ & $70.4 \mathrm{ab}$ & $27.5 \mathrm{a}$ & $4.14 \mathrm{ab}$ \\
\hline FPI & $11.82 \mathrm{ab}$ & $5.8 \mathrm{a}$ & $65.1 \mathrm{ab}$ & $28.1 \mathrm{a}$ & $4.03 \mathrm{ab}$ \\
\hline GDC & $8.53 b$ & $5.5 \mathrm{a}$ & $43.6 \mathrm{~b}$ & $26.8 \mathrm{a}$ & $2.63 \mathrm{~b}$ \\
\hline GDI & $8.25 \mathrm{~b}$ & $5.3 \mathrm{a}$ & $43.3 \mathrm{~b}$ & $26.6 \mathrm{a}$ & $2.63 \mathrm{~b}$ \\
\hline CV (\%) & 13.8 & 9.2 & 9.0 & 12.7 & 17.0 \\
\hline
\end{tabular}

Médias nas colunas seguidas da mesma letra não diferem significativamente pelo teste de Tukey. NV = número de vagens; NG = número de grãos; M100G = massa de 100 grãos; FPI = feijão de porco isolado; FPC = feijão de porco consociada; $\mathrm{MUI}=$ mucuna isolada; $\mathrm{MUC}=$ mucuna consorciada; $\mathrm{CJI}=$ crotalaria juncea isolada; $\mathrm{CJC}=$ crotalaria juncea consorciada; GDI = feijão guandu isolada; GDC $=$ feijão guandu consorciado.

Em relação ao NGP e M100G não foram observadas diferenças significativas entre os tratamentos. A mucuna consorciada com milheto apresentou uma diferença significativa de produção de $1.778 \mathrm{~kg} \mathrm{ha}^{-1}$ em relação ao guandu consorciado, atingindo mais de $4.000 \mathrm{~kg} \mathrm{ha}^{-1}$. A produção de grãos média observada foi de $3.735 \mathrm{~kg} \mathrm{ha}^{-1}$, o que representa uma produtividade quatro vezes superior à média nacional, que no ano de 2010 foi de $910 \mathrm{~kg} \mathrm{ha}^{-1}$ (CONAB, 2015) ${ }^{1}$.

Em trabalho conduzido por Cunha et al. (2011) para determinar o efeito de diferentes sistemas de manejo do solo e plantas de cobertura na produção orgânica de feijão e milho em condições semelhantes de solo e clima deste trabalho, o rendimento de grãos do feijoeiro e do milho não foi alterado pelas culturas de cobertura nos dois sistemas de preparo do solo, semeadura direta e manejo convencional do solo. Ferreira et al. (2011a) e Almeida et al. (2008) também não observaram efeito da crotalária e do sorgo na produtividade do feijoeiro comum sob sistema orgânico de produção; contudo, os autores reportaram uma produtividade $33 \%$ maior em sistema de plantio direto em relação ao manejo convencional do solo.

Em relação ao tipo de manejo do solo, foram observados efeitos significativos para as variáveis $\mathrm{NV}$, NGP e para a produção de grãos, sendo os maiores valores encontrados sob plantio direto (Tabela 2). Os valores obtidos para produtividade foram superiores em $609.89 \mathrm{~kg} \mathrm{ha}^{-1}$ em semeadura direta com relação ao manejo convencional, e superiores aos apresentados por Abbadia et al. (2011) com a cultivar BRS supremo em sistema de manejo orgânico, onde a produção sob sistema de semeadura direta superou a produção sob sistema de manejo convencional, alcançando

Tabela 2. Componentes de rendimento e produção de grãos em feijoeiro comum em função do sistema de manejo do solo.

\begin{tabular}{lccccc}
\hline Manejo & NV & NG & NG & M100G & Produção \\
\hline & Planta & Vagem & Planta & Mg ha & \\
Sistema plantio direto & $12.4 \mathrm{a}$ & $5.9 \mathrm{a}$ & $68.1 \mathrm{a}$ & $34.7 \mathrm{a}$ & $4.05 \mathrm{a}$ \\
Sistema convencional & $10.6 \mathrm{~b}$ & $5.7 \mathrm{a}$ & $56.7 \mathrm{~b}$ & $27.9 \mathrm{a}$ & $3.44 \mathrm{~b}$ \\
CV $(\%)$ & 13.8 & 9.2 & 9.5 & 12.7 & 17.55 \\
\hline
\end{tabular}

Médias nas colunas seguidas da mesma letra não diferem significativamente pelo teste de Tukey. $\mathrm{NV}=$ número de vagens; $\mathrm{NG}=$ número de grãos; $\mathrm{M} 100 \mathrm{G}=$ massa de 100 grãos.

${ }^{1}$ CONAB (Companhia Nacional de Abastecimento). 2015. Acompanhamento de safra brasileira: Grãos, quarto levantamento, janeiro 2010. Companhia Nacional de Abastecimento. Brasília. 
$2.268 \mathrm{Mg} \mathrm{ha}^{-1}$. Segundo os autores, a produtividade alcançada em sistema de plantio direto foi 3.28 vezes maior que a produtividade observada no sistema de manejo convencional do solo, sendo determinado em função dos maiores valores encontrados neste sistema para os componentes de produtividadenúmero de vagem, número de grãos e massa de 100 grãos. Neste contexto muitos autores asumem que em agricultura orgânica a produtividade se incrementa a largo prazo, alegando menor e lento aporte de os nutrientes ao sistema, pelo tem sido comprovado cientificamente que quando os sistemas agrícolas alcançam a sustentabilidade e estabilidades de suas fertilidades, os produtividades das culturas se incrementam. Os estudos preliminares da agricultura orgânica mostram que existe viabilidade técnica e econômica para estabelecimento da produção orgânica usando o plantio direto (Wander et al., 2007).

De maneira geral para alcançar incremento da produção da cultura de feijão em sistema orgânico é necessário lograr a estabilidade do sistema em o tempo, promovendo o uso dos consórcios, os adubos verdes, os esquemas de rotação, fertilização orgânica, com fim de recuperar e conservar o solo, estimular o incremento do uso de médios biológicos em o combate de pragas, tudo isto para destaque da importância de usar práticas de manejo, em equilíbrio com a natureza, para aproveitar as potencialidades produtivas locais, e fazer ênfases em que cada camponês produza seu próprio adubo orgânico: compostagem-húmus, para aproveitar os resíduos e suprir o solo.

Em tal sentido pode-se inferir que os elevados resultados na produção de feijão nos sistemas de manejo do solo estudado, é resultado em parte aos antecedentes do manejo agroecológico da área por vários anos com adubos verdes usando leguminosas e gramíneas consorciadas e sim consorciar, uso de fertilizantes de origem orgânico, controles biológicos e biopreparados para controle de pragas, de conjunto com boas atenções fitotécnicas as culturas, como irrigação e capina.

Segundo Dueñas et al. (2011) em condições de clima tropical, a cobertura do solo tem una ação protetora por a intercepção e absorção do impacto direto das gotas de chuva, o que previne o selado da superfície e preserva a estrutura do solo, como também estabiliza a capacidade infiltração do água durante a ocorrência de eventos meteorológicos, tudo contribui para melhor umidade no solo e incrementos na produção da cultura.

A Figura 1 apresenta o dendrograma construído a partir dos componentes de rendimento e da produção de grãos do feijoeiro comum em função das plantas de cobertura e dos sistemas de manejo do solo. A análise de agrupamento por dendrograma foi usando a Distância

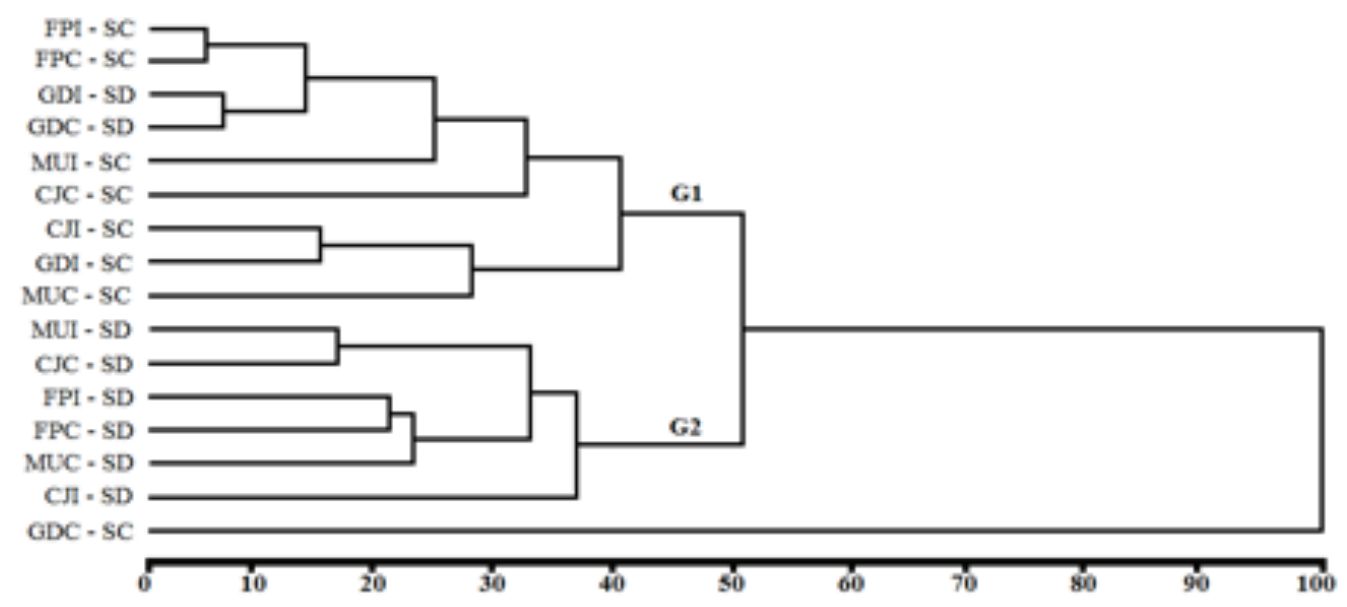

Figura 1. Análise de agrupamento por dendrograma construído usando a Distância Euclidiana média como coeficiente de dissimilaridade e UPGMA (Unweighted Pair Group Method with Arithmetic Mean) como método de agrupamento, realizada a partir dos componentes da produtividade e da produção de grãos do feijoeiro comum em função das plantas de cobertura e dos sistemas de manejo do solo. $\mathrm{FPI}=$ feijão de porco isolado; FPC = feijão de porco consociada; $\mathrm{MUI}=$ mucuna isolada; MUC = mucuna consorciada; CJI = crotalariajuncea isolada; CJC = crotalariajuncea consorciada; GDI = guandu isolada; GDC = guandu consorciado; $\mathrm{SC}=$ sistema convencional; $\mathrm{SD}=$ semeadura direta. 
Euclidiana média como coeficiente de dissimilaridade e UPGMA (Unweighted Pair Group Method with Arithmetic Mean) como método de agrupamento, realizada a partir dos componentes da produtividade e da produção de grãos do feijoeiro comum em função das plantas de cobertura e dos sistemas de manejo do solo. O tratamento GDC-SC apresentou $100 \%$ de dissimilaridade em relação aos demais, ou seja, não apresenta nenhuma similaridade com o resto dos tratamentos. Com 50\% de dissimilaridade foram formados dois grupos principais (G1 e G2). No grupo G1 predominam os tratamentos sob manejo convencional do solo e no grupo G2 os tratamentos sob semeadura direta. Os tratamentos mais similares entre si foram FPI-SC e FPC-SC, seguidos de GDISD e GDC- SD. Dentro de cada grupo aparecem outros agrupamentos com maior similaridade. Dentro do grupo G1, a um nível de dissimilaridade de $25 \%$ formam-se dois subgrupos, contendo os tratamentos FPI-SC, FPC-SC, GDI-SD, GDC-SD em um subgrupo, no qual as plantas de cobertura foram determinantes para este agrupamento; e CJI-SC, GDI-SC e MUC-SC no outro subgrupo, formado em função do sistema de manejo do solo.

Já no grupo G2 são formados dois subgrupos, contendo os tratamentos MUI-SD e CJC-SD e no outro subgrupo os tratamentos FPI-SD, FPC-SD e MUC-SD. Ambos os grupos foram formados sem efeito aparente das plantas de cobertura, mas com grande influência do sistema de manejo do solo.

A análise de agrupamento por dendrograma de dissimilaridade evidenciou o efeito dos sistemas de manejo do solo no agrupamento dos tratamentos e um efeito discreto das plantas de cobertura na formação de subgrupos. Em trabalho realizado para avaliar o efeito das plantas de cobertura e de sistemas de manejo do solo sobre indicadores microbianos da qualidade do solo, Ferreira et al. (2011b) não encontraram efeito das plantas de cobertura na formação de grupos principais nem subgrupos, mas sim influência dos sistemas de manejo na conformação dos grandes grupos principais. Apesar disso, Rutigliano et al. (2004), consideraram as culturas da cobertura como fator chave para alteração das propriedades do solo, em função das espécies de plantas que exercem um efeito mais pronunciado nos sistemas de manejo.

\section{CONCLUSÕES}

$\mathrm{O}$ número de vagens, número de grãos e a produtividade do feijoeiro comum cultivado em sistema orgânico são influenciados pelas plantas de cobertura do solo e pelos sistemas de manejo do solo, com destaque para a mucuna consorciada com milheto e do sistema de plantio direto que proporcionaram melhor desempenho destes parâmetros.A maior produção de grãos foi observada com a mucuna consorciada com milheto em sistema de plantio direto. A produtividade média do feijoeiro orgânico foi de $3.8 \mathrm{Mg} \mathrm{ha}^{-1}$. A análise de agrupamento revela um efeito marcante dos sistemas de manejo do solo sobre os componentes de produtividade do feijoeiro comum.

\section{REFERÊNCIA}

Abbadia, J. P., E. P. Ferreira de Brito, A. A. Wendland, e A. D. Didonet. 2011. Produção de grãos e relação com reação a doenças em feijoeiro comum cultivado em sistema de manejo orgânico. pp. 1-3. In: Congresso Nacional de Pesquisa De Feijão CONAFE. Anais. Universidade Federal de Goiás. Embrapa Arroz e Feijão. Goiânia, Brasil.

Almeida, V. P., M. C. Alves, E. Cabral da Silva, e S. A. Oliveira. 2008. Rotação de culturas e propriedades físicas e químicas em Latossolo Vermelho de cerrado sob preparo convencional e semeadura direta em adoção. Rev. Bras. Ciênc. Solo 32: 1227-1237.

Ambrosano, J. E., F. Rossi, N. Guirado, e P. C. D. Mendes. 2004. Adubação verde em sistemas agroecológicos para agricultura familiar. pp. 32-69. In: Curso de capacitação em agricultura orgânica. Impresso Especial Cati. Piracicaba- São Paulo, Brasil.

Cunha, E. Q., L. F. Stone, J. A. A. Moreira, E. P. B. Ferreira, A. D. Didonet, e W. M. Leandro. 2011. Sistemas de preparo do solo e culturas de cobertura na produção orgânica de feijão e milho. I-Atributos físicos do solo. Rev. Bras. Ciênc. Solo 35: 589-602.

Dueñas, R. M., E. G. Corrales, e R. O. Gallego. 2011. Uso de materiais locais como arroupe para contribui a eficiência dos sistemas produtivos. Agric. Org. 1: 35- 36.

Ferreira, E. P. B., L. F. Stone, F. L. Partelli, e A. D. Didonet. 2011a. Produtividade do feijoeiro comum influenciada por plantas de cobertura e sistemas de manejo do solo. Rev. Bras. Eng. Agríc. Amb. 15: 695-701.

Ferreira, E. P. B., A. Wendland, e A. D. Didonet. 2011b. Microbial biomass and enzyme activity of a Cerrado Oxisol under agroecological production system. Bragantia 70: 899-907. 
Giacomini, S. J., C. Aita, E. R. O. Vendruscolo, M. Cubilla, R. S., Nicoloso, e M. R. Fries. 2003. Matéria seca, relação C/N e acúmulo de nitrogênio, fósforo e potássio em misturas de plantas de cobertura de solo. Rev. Bras. Ciênc. Solo 27: 325-334.

Gonçalves, W. G., R. L. Jimenez, J. V. Araújo-Filho, R. L. Assis, G. P. Silva, e F. R. Pires. 2006. Sistema radicular de plantas de cobertura sob compactação do solo. Eng. Agríc. 26: 67-75.

Nogueira, R. G., D. Fornasieri Filho, F. Minto Boldieri, D. A. Cazetta, J. A. de Souza Rossato Júnior, e R. Vieira Marchiori. 2006. Influência das culturas de cobertura morta e de nitrogênio sobre componentes produtivos do feijoeiro de inverno em sucessão ao milho. Cient. Jaboticabal 34: 115-122.

Oliveira, T. K., G. J. Carvalho, e R. N. de Souza Moraes. 2002. Plantas de cobertura e seus efeitos sobre o feijoeiro em plantio direto. Pesq. Agropec. Bras. 37: 1079-1087.

Posse, S. C. P., E. M. Riva-Souza, G. M. da Silva, L. M. Fasolo, M. B. da Silva, e M. A. M. Rocha. 2010. Informações técnicas para o cultivo do feijoeiro-comum na região central- brasileira: 2009 - 2011. pp. 40-45. In: Incaper, Documentos 191. Instituto de Pesquisa. Assistência técnica e extensão Rural. Vitória. Brasil.
StatSoft. 2011. Statistica. System reference. StatSoft. Tulsa, OK, USA.

Silva, S. C., A. B. Heinemann, R. L. F. Paz, e A. O. Amorim. 2010. Informaciones meteorológicas para investigación y planificación agrícola, referentes al año 2009, del municipio de Santo Antonio de Goiás, GO. Embrapa Arroz e Feijão. Documentos 256. Santo Antônio de Goiás, Brasil.

Timossi, P. C., J. C. Durigan, e G. J. Leite. 2007. Formação de palhada por braquiárias para adoção do sistema plantio direto. Bragantia Campinas 66: 617-622.

Rutigliano, F. A., R. D’Ascoli, e A.V. Santo. 2004. Soil microbial metabolism and nutrient status in a Mediterranean area as affected by plant cover. Soil Biol. Biochem. 36: 1719-1729.

Wander, A. E., A. D. Didonet, J. A. A. Moreira, F. P Moreira, A. C. Lanna, J. A. F. Barrigossi, E. D. Quintela, e T. R. Ricardo. 2007. Economic viability of small scale organic production of rice common bean and maize in Goiás State, Brazil. J. Agric. Rural Develop. Trop. Subtrop. 108: 51-58. 